\title{
Methods for assessing cough sensitivity
}

\author{
Yonglin Mai ${ }^{1,2 \#}$, Liman Fang ${ }^{1 \#}$, Shuxin Zhong ${ }^{1}$, S. Dushinka Shaniya Helen de Silva ${ }^{1,3}$, Ruchong Chen ${ }^{1}$, \\ Kefang Lai ${ }^{1}$
}

${ }^{1}$ State Key Laboratory of Respiratory Disease, National Clinical Research Center for Respiratory Disease, Guangzhou Institute of Respiratory Health, the First Affiliated Hospital of Guangzhou Medical University, Guangzhou, China; ${ }^{2}$ Nanshan School of Medicine, Guangzhou Medical University, Guangzhou, China; ${ }^{3}$ International College of Education, Guangzhou Medical University, Guangzhou, China

Contributions: (I) Conception and design: R Chen, K Lai; (II) Administrative support: None; (III) Provision of study materials or patients: None; (IV) Collection and assembly of data: None; (V) Data analysis and interpretation: None; (VI) Manuscript writing: All authors; (VII) Final approval of manuscript: All authors.

\#These authors contributed equally to this work

Correspondence to: Prof. Ruchong Chen; Prof. Kefang Lai. State Key Laboratory of Respiratory Disease, National Clinical Research Center for Respiratory Disease, Guangzhou Institute of Respiratory Health, the First Affiliated Hospital of Guangzhou Medical University, Guangzhou, China. Email: chen_rch@163.com; klai@163.com.

\begin{abstract}
Cough sensitivity can be described as the reaction intensity of the cough reflex to different stimuli which activate chemically and mechanically sensitive vagal afferent nerves innervating airways and lungs. Measurement of cough reflex sensitivity plays an important role in revealing the underlying mechanisms of cough and evaluating the effects of pharmacological interventions. Besides, different responses to cough suppression therapies indicate the existence of cough hypersensitivity. In consideration of these factors stated above, cough sensitivity should therefore be assessed with a variety of cough challenge tests. Based on the neuroanatomical characteristics of the cough reflex, chemical challenge tests have been developed to objectively assess cough sensitivity. In cough inhalation challenges, capsaicin and citric acid are commonly used as the tussive agents to induce cough, which are validated for describing a profile of cough sensitivity to chemical irritants. Recently, mechanical methodologies have also been tried to measure the mechanical sensitivity of the cough reflex. Methodological consideration and selection are necessary for the reasonable assessment of cough sensitivity while employing cough challenges in clinical trials. Thus, in this review, we will focus on describing various methodologies of cough sensitivity measurement and, detailing some factors influencing on the accuracy of outcomes in the experimentally induced cough.
\end{abstract}

Keywords: Cough sensitivity; assessment; inhalation challenges; mechanical challenges

Submitted Apr 16, 2020. Accepted for publication Jul 25, 2020.

doi: $10.21037 /$ jtd-2020-icc-005

View this article at: http://dx.doi.org/10.21037/jtd-2020-icc-005

\section{Introduction}

Cough is the most common symptom for patients to seek health care, which affects approximately 10 percent of adults per annum in worldwide health care centers (1). At least $30 \%$ of patients are suffering from chronic cough in the respiratory specialist visits (2). Regarding the clinical significance of cough, some cough measurement tools have been established to measure cough, including subjective and objective methods. The subjective evaluation tools of assessing the cough severity mainly include the cough scores, visual analogue scale (3) and QoL questionnaires like the Leicester cough questionnaire (LCQ) (4), coughspecific quality of life questionnaire (CQLQ) (5) etc. They are easy to score and also practical for a longitudinal comparison in clinical practice. However, they are susceptible to individual factors and are unlikely to be used for a horizontal comparison. Besides, cough can be assessed objectively with cough frequency monitoring and cough challenge tests. Cough monitoring records cough 
frequency and sounds, which can be applied to both the longitudinal and horizontal comparisons (6,7). But cough monitoring requires a special device, which will be laborconsuming and time-costing $(8,9)$. On the contrary, cough challenge test is another objective method. It is widely used to measure cough sensitivity and evaluate the effect of a pharmacological intervention in cough researches, revealing the underlying mechanisms of cough.

Cough sensitivity is defined as the reaction intensity of the cough reflex to different stimuli. Cough can be elicited by the activation of chemically and mechanically sensitive vagal afferent nerves projecting to airways and lungs (C-fibers and A $\delta$-fibers) (10,11). Vagal sensory nerve terminals mainly express different types of receptors respond to different stimulants, which include C-fibers receptors and mechanoreceptors [rapidly adapting receptors (RARs) and slowly adapting receptors (SARs)]. C-fibers receptors are primarily chemically sensitive. Chemically sensitive C-fibers receptors respond to a variety of chemical mediators, such as critic acid, capsaicin, cigarette smoke or proinflammatory mediator bradykinin $(12,13)$. Furthermore, RARs and SARs are dynamic airway mechanoreceptors which can be activated by smooth muscle contraction in the airway and punctate mechanical stimuli, such as bronchospasm, the inflation and deflation of lungs or acute mechanical distortion of the airway walls $(11,14,15)$. Based on the neurophysiological characteristics of the cough reflex, a range of approaches have been established to measure the cough sensitivity by activating related neuropathways.

A heightened cough reflex is commonly seen in patients with chronic cough, which is suggestive of cough-reflex hyperresponsiveness. Cough hypersensitivity syndrome (CHS) is defined as heightened cough reflex which is often triggered by low levels of thermal, mechanical or chemical exposure (16). In different cough sensitivity measurement tests, patients with CHS present heterogeneity in cough hypersensitivity to heterogeneous irritants, including different tussive agents capable of eliciting cough and related respiratory behaviors. Given the heterogeneous mechanistic processes driving cough hypersensitivity, assessing the sensitivity of cough reflex is beneficial to decipher the mechanisms driving cough hypersensitivity across different patients and different clinical contexts. It would be key to making further advances in discovering the antitussive drug and evaluating therapeutic effect. Furthermore, the cough reflex is a defense mechanism of the airways. The impairment in cough reflex may lead to a higher risk of aspiration pneumonia and pulmonary infection in the patients with cancer radiotherapy of head and neck cancer, as well as nervous system diseases, like stroke, dementia, Parkinson disease etc. $(17,18)$. The higher risk of pneumonia is associated with the decreased urge-tocough (UTC) or voluntary cough $(18,19)$. Cough sensitivity evaluation is also essential to evaluate the function of cough reflex.

Currently, there is a paucity of standardized approaches to quantify cough sensitivity and a number of centers employ different methods which complicates assessing cough sensitivity. Therefore, this review aims to detail different tussive agents in cough inhalation tests and introduce some noninvasive mechanical measurements in evaluating cough reflex sensitivity (Figure 1).

\section{Methods of assessing cough sensitivity}

The methods of assessing cough sensitivity are based on chemical or mechanical stimulation of cough receptors, which can produce nerve impulses of cough induction. The levels of cough reflex sensitivity could be assessed by comparing the intensity of stimulus (concentration, dose, etc.) or the response to irritants (cough frequency, occurrence time, etc.).

\section{Cough inhalation challenges}

Cough inhalation challenges have been developed for several decades. A variety of tussive agents have been used to induce cough mainly by activating $\mathrm{C}$-fibers. The most commonly used tussive agents include capsaicin and citric acid. Experimentally induced cough was also described using other irritants like ATP, mannitol, distilled water etc.

\section{The methods of inhalation}

The methods of inhalation are divided into single-dose and dose-response challenge (12). In the single-dose inhalation challenge, single concentration of tussive agents is delivered. It is simple and timesaving without severe side effects, which is beneficial for its application in the epidemiological surveys. Depending on the length of inhalation, the dose-response challenge includes two types of inhalation methods. One method is the single, vital-capacity breaths of incremental concentrations of nebulized tussive agents controlled by a dosimeter. The other method is the tidalbreath inhalations of incremental concentrations of tussive agents during a fixed time period (15-60 seconds). 


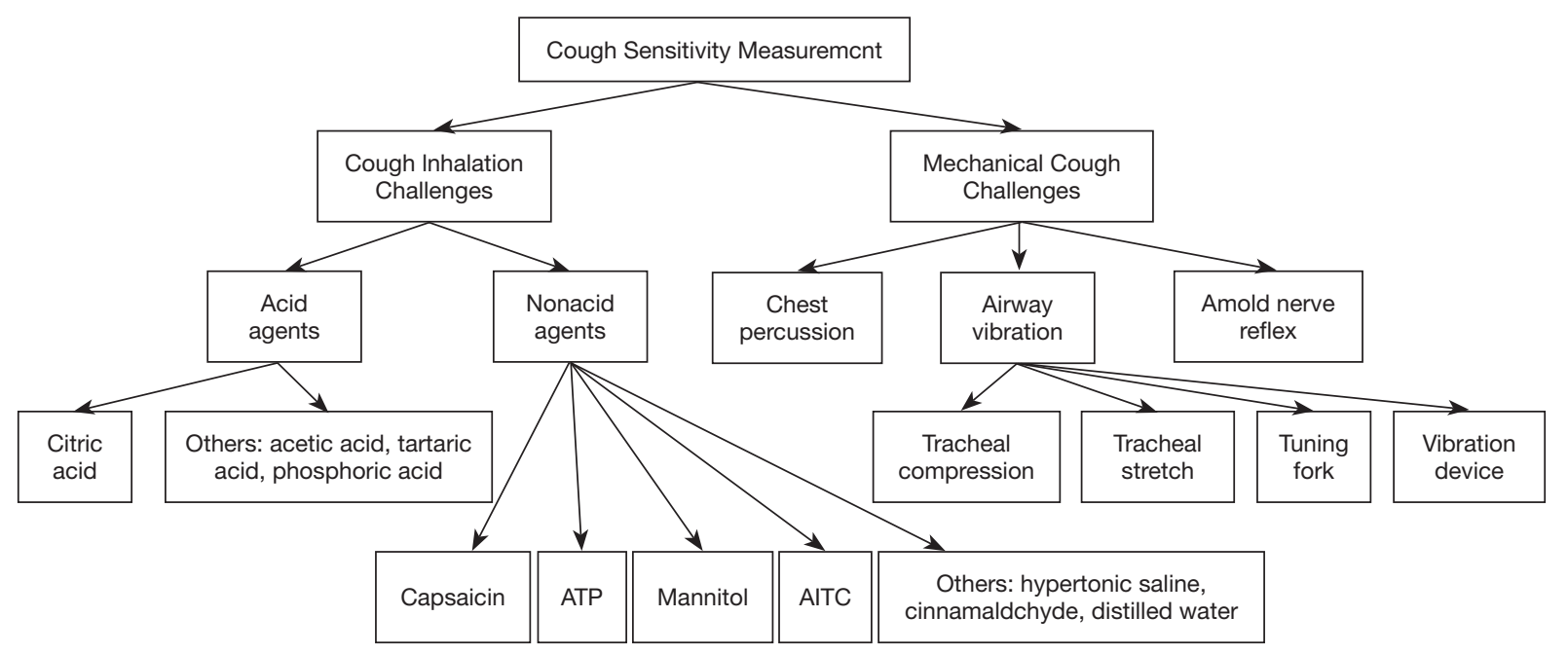

Figure 1 An overview of methodologies of cough sensitivity measurement. ATP, adenosine triphosphate; AITC, allyl isothiocyanate.

In the fixed-time dose-response challenge, it is difficult to measure the accurate amounts of tussive agents delivered from nebulizers due to the long inhalation period. An individual's breathing effort, tidal volume or type of nebulizer used may potentially affect the amount of the delivery of tussive agents in each inhalation (20). Thus, the factors mentioned above, limit its wider usage in testing cough sensitivity. According to some guidelines, the single breath method has acquired a recommendation because of its accuracy and reproducibility of the dose delivery. When employing the single-breath, dose-response challenge, placebo or contrast inhalations will be randomly interspersed between incremental concentrations of tussive agents to increase challenge blindness and minimize potential bias. As to record the results, it is suggested to count the number of coughs occurring in the initial 15 or 30 seconds (less than 1 minute) because cough elicited by tussive agents is usually immediate and transient (21).

Based on the methods introduced above, recently, some affordable and portable devices were developed and applied to measure cough reflex sensitivity to tussive agents. Curtis et al. developed a handheld cough testing (HCT) to measure cough airflow and sensation, which is a novel tool comprised of a facemask connected to a handheld nebulizer and an analog peak flow meter (22). Furthermore, a novel device was applied by Fujiwara which easily and simultaneously measures the time until the cough reflex and the strength of involuntary coughs, which consists of a special pipe with a double lumen, a nebulizer, and an electronic spirometer (23). The effectiveness of these equipment still needs to be verified.

\section{Tussive agents}

Non-acid tussive agents

\section{Capsaicin}

Capsaicin, an acylated homovanillic acid extracted from red peppers, mainly acts on the transient receptor potential vanilloid-1 (TRPV1) expressed in nonmyelinated C-fibers and some myelinated A $\delta$-fibers (24). Capsaicin-evoked cough is associated with the activation of TRPV1, which increases the intracellular concentration of $\mathrm{Ca}^{2+}$ resulting in the depolarization of neurons and the release of neurotransmitters (12). With good specificity, repeatability and safety, capsaicin cough challenge has been applied to study cough response since 1980s. Capsaicin cough challenge test is a reproducible and safe method for assessing cough reflex sensitivity. Nieto described that the capsaicin cough challenge test in healthy controls showed a great reproducibility (25). Moreover, the high degree of short- and long-term reproducibility was confirmed by Dicpinigaitis (21). In terms of safety, a review of more than two decades of clinical experience did not report serious adverse events related to capsaicin inhalation (26). A recent survey showed that in some patients with severe asthma, capsaicin inhalation challenge appears to be safe and tolerable which did not cause bronchoconstriction (27).

To date, capsaicin is the most commonly used non-acid tussive agent in the cough inhalation challenges. Capsaicin inhalation challenge is recommended to investigate the role of TRPV1-mediated cough mechanisms and the predictive 
value of novel antitussive agents by several guidelines like the European Respiratory Society (ERS), American College of Chest Physician (ACCP), Chinese Thoracic Society (CTS) etc. (28-30). It has been demonstrated that capsaicin cough sensitivity is heightened in patients with respiratory diseases [e.g., postinfectious cough (PIC), gastroesophageal reflux related cough (GERC), chronic refractory cough etc.], indicating that cough hyperresponsiveness is associated with TRPV1-mediated pathway $(25,31,32)$. Therefore, TRPV1 antagonisms may be novel pharmacological targets for suppressing cough. However, recent studies show that SB705498 as a TRPV1 antagonist significantly improves the cough reflex hypersensitivity to capsaicin, but did not reduce cough frequency in patients with chronic cough (33). These findings are consistent with the results of treatment with another TRPV1 antagonists XEN-D0501 (34). Whether TRPV1 can be an effective therapeutic target for chronic cough still needs to be further evaluated. Capsaicin cough sensitivity can also be improved by medications, including sulindac (35), zafirlukast (leukotriene receptor antagonist) (36), baclofen (a GABA-agonist) (37), inhaled menthol (38) and tiotropium (39) etc. Furthermore, capsaicin inhalation challenge can also be used to evaluate the cough reflex sensitivity of patients with neurodegenerative diseases and cancer radiotherapy, since the impairment of the cough reflex will lead to a higher risk of aspiration pneumonia.

\section{Adenosine 5'-triphosphate (ATP)}

ATP, an intracellular purine nucleotide, interacts with $\mathrm{P} 2 \mathrm{X} 3$ and possibly other $\mathrm{P} 2 \mathrm{X}$ receptors presenting on the terminals of airway sensory nerves (40). Aerosolized ATP is employed to produce a tussive response in the measurement of cough reflex sensitivity. For the ATP inhalation challenge, the chronic cough patients had a greater cough response at lower concentrations of ATP than healthy subjects (41). However, the safety and repeatability of the ATP inhalation challenge still needs to be further confirmed because ATP inhalation can potentially yield bronchoconstriction (42). In addition, Morice et al. found that gefapixant (formerly named AF-219, P2X3 antagonist) could alleviate cough induced by ATP and distilledwater, but not capsaicin and citric acid (43). Bonvini identified the TRPV4-ATP-P2X3 interaction involved in cough hypersensitivity in the guinea pig conscious cough models (44). These findings suggest that TRPV4/ATP pathway may underlie cough hypersensitivity in chronic refractory cough. Thus, the TRPV4-ATP-P2X3 pathway appears to be a novel therapeutic target for chronic cough. In the phase 2 clinical study with $\mathrm{P} 2 \mathrm{X} 3$ antagonists, the result described that $\mathrm{AF}-219$ significantly improved cough frequency and cough severity in patients with chronic refractory cough without serious adverse events (45). Moreover, DT-0111, as a selective antagonist at P2X2/3R, may be another drug-candidate for treating COPD and chronic cough (46).

\section{Mannitol}

Mannitol is a polyol sugar (20) extracted from brown algae cells, which is mainly used to be a provocative agent for bronchial provocation test $(47,48)$. However, the mechanisms of mannitol-provoked cough remain unclear. Koskela et al. demonstrated that the cough response to mannitol in asthma was independent of bronchoconstriction, implying that hyperosmolarity might activate $\mathrm{C}$-fibers and release sensory neuropeptides which in turn stimulate RARs. This study also indicated that mannitol could stimulate the airway epithelial cells to release an acid and then activate airways C-fibers (49). The most probable receptor resulting from hypertonicity is TRPV4 (50). The safety and efficacy of mannitol challenge test have been proved in asthmatic patients (48). Recent studies demonstrated that subjects with chronic cough could be separated from healthy subjects and from subjects with other airway symptoms (dyspnea or wheezing) by the cough sensitivity to mannitol inhalation challenge. Furthermore, the mannitol cough sensitivity was correlated with subjective symptoms presented by the cough related life quality questionnaire LCQ (51).

\section{Others}

Hypertonic saline has been used for bronchial provocation test to assess bronchial hyperresponsiveness for decades. Cough inhalation challenge has also been developed to measure cough sensitivity. Hypertonic saline probably stimulates A $\delta$ and C-fibers in the guinea-pig models (52). The hypertonic saline-associated cough response is not dependent on induced bronchoconstriction. A research found that cough response to hypertonic saline was more prevalent than hypertonic saline-associated bronchoconstriction in asthmatic patients (53). Another study using salbutamol pre-treatment also showed cough sensitivity to hypertonic saline seems to be enhanced in asthmatic patients (54). Collectively, as a simple, cheap and noninvasive tool, hypertonic saline challenge may be a benefit for managing the patients with airway hyperresponsiveness (53).

Ultrasonically nebulized distilled water (UNDW) was originally used to experimentally induce bronchoconstriction in asthmatic patients. Moreover, the 
UNDW cough challenge has also been applied to measure cough sensitivity because healthy controls and patients with airway hyperreactivity could be provoked severe cough by UNDW (55). It was demonstrated that UNDW-induced cough was not dependent on bronchoconstriction (56). The mechanism of distilled water to provoke cough is probable to excite $\mathrm{A} \delta$ and $\mathrm{C}$ fibers (52). The short- and long-term reproducibility of cough sensitivity and cough frequency has been demonstrated in humans while employing cough inhalation challenge with UNDW (57). However, as to safety of UNDW challenge, UNDW potentially provokes bronchoconstriction in susceptible subjects (58).

Allyl isothiocyanate (AITC), a common natural isothiocyanate, is enzymatically refined from black mustard oil (59). AITC selectively activates TRPA1 of tracheal jugular $\mathrm{C}$ fibers in vivo (60). As a selective TRPA1 agonist, AITC has been applied in AITC cough challenge as a measure the sensitivity of TRPA1-mediated cough reflex. However, it is less effective to employ the TRPA1 activators AITC in inducing cough compared to the TRPV1 agonist capsaicin and citric acid (60). Moreover, it was proved that AITC cough challenge might provide a safe method to assess cough reflex sensitivity because of its good safety and tolerability (32). Recently, as interest in TRPA1 grows, it may appear to be a novel target for tussive agents. The cough associated with AITC can be inhibited by the TRPA1 antagonist AP-18 (60), HC-030031 (61), and AMG0902 (62).

Cinnamaldehyde extracted from cinnamon was initially regarded as a TRPA1 agonist of cough induction test in animal models and human volunteers (63). However, cinnamaldehyde was proved to be twofold more effective in cough induction than another TRPA1 agonist AITC. Cinnamaldehyde-induced cough can be partially inhibited by TRPA1 antagonist AP-18 but disappeared while using the combination of TRPA1 antagonist AP-18 and TRPV1 antagonist I-RTX. These findings implied that cinnamaldehyde induced cough via both TRAV1 receptors and TRPA1-mediated mechanisms (60). The good reproducibility and less tachyphylaxis of cinnamaldehyde cough challenge has been demonstrated by Birrel (63).

\section{Acid tussive agents}

\section{Citric acid}

Citric acid is the earliest and most widely used acid tussive agent which has also been used as a cough provocation test since 1950s. Patients with chronic cough can be triggered more cough by citric acid compared to healthy subjects, presenting a heightened cough sensitivity. However, mechanisms of cough response to citric acid inducing cough have not been fully elucidated. Citric acid probably acts on jugular C-fibers and nodose A $\delta$-fibers (64). TRPV1 is thought to be involved in the development of cough response to citric acid (28). Competitive TRPV1 antagonist Capsazepine could have an inhibitory effect on citric acidevoked cough in guinea pigs, revealing that the activation of TRPV1 is related to cough induced by citric acid (65). Besides, other candidate receptors have also been suggested, including acid sensing ion channels (ASIC) or other members of TRP family (e.g., TRPA1, TRPV4) $(66,67)$.

With good safety, feasibility and tolerability, the citric acid inhalation challenge was suggested to assess cough reflex sensitivity in response to cough therapies and pharmacological studies of potential antitussive meditations $(68,69)$. ERS guideline recommended the breath-activated dosimeter (KoKo DigiDoser system) by comparing the citric acid challenge with two different methodologies and investigating the intra-study and inter-day variability (28). Citric acid could be delivered using a compressed air-driven nebulizer controlled by The KoKo Digidoser system. Citric acid challenge test is highly reproducible in the short and medium term in the pharmaceutical studies. Meanwhile, menthol inhalation (70), diphenhydramine (71), memantine (72), lidocaine (73), as well as oral codeine analogue dextromethorphan (74) were proved to improve citric acidinduced cough.

\section{Others}

Acetic acid, phosphoric acid, and tartaric acid has also been used as a tussive stimuli. Wong revealed a significant correlation of citric acid-evoked cough with cough response to acetic acid and phosphoric acid. Thus, both acetic acid and phosphoric acid might share a similar mechanism to citric acid in triggering cough via the production of a low $\mathrm{pH}$ (high proton concentration) (75). Inhalation of acid triggers cough may be related to the activation of protongated ion channels of vagal sensory nerves (76). Many factors have a potential influence on acid-introduced cough, including gender (77), inhaled furosemide and amiloride (78) as well as oral mexiletine (79). In terms of safety, acid inhalation tests are generally safe methods (75). But the reproducibility of these acidic tussive agents is incompletely understood.

\section{End points of inhalation cough challenge}

In the dose-response challenge, cough sensitivity can be presented as the cough threshold which is taken as the lowest concentration of stimulus capable of eliciting 
cough in two challenges with a 30-minute interval (80). The most commonly employed end points of cough inhalation challenges are C2 and C5 determined by the lowest concentration of capsaicin (or citric acid) inducing at least two or five coughs respectively (28). Overall, the reproducibility of $\mathrm{C} 2$ and $\mathrm{C} 5$ values is optimal. But $\mathrm{C} 5$ has a better short-term reproducibility than that of $\mathrm{C} 2$, suggesting that $\mathrm{C} 5$ is the preferred end point in the cough challenges performed within a 14-day interval. The results were consistent with those at study intervals of 6 months (21). Besides, C5 is the preferred end point which is less susceptible to subjective factors and better reflects the involuntary cough sensitivity to tussive agents.

However, C2/C5 values have limited functions on revealing the pathophysiologic mechanisms of cough because of a weak correlation with $\mathrm{C} 2 / \mathrm{C} 5$ and cough counts, and a sustainable overlap between disease and health. Recently, Hilton et al. has put forward other dose-response parameters, $\mathrm{ED}_{50}$ and $\mathrm{E}_{\max }$ values with a nonlinear mixed-effects modeling to characterize capsaicin dose response in patients (81). ED50 is taken as the dose inducing half-maximal cough response in the dose-response curve. $\mathrm{E}_{\max }$ is described as any concentrations evoking the maximum cough response, which reflects the maximal capacity of a subject to cough. Compared with healthy and asthmatic subjects, patients with chronic cough presented an increased $\mathrm{E}_{\max }$ value but a decreased $\mathrm{ED}_{50}$ value. Besides, $\mathrm{E}_{\max }$ value has been demonstrated to be a stronger predictor of spontaneous 24-hour frequency than $\mathrm{ED}_{50}$ value $(81,82)$. Satia et al. reported that $\mathrm{E}$ values could not be significantly influenced by age, weight, atopy and lung physiology and so on (82). Thus, $\mathrm{ED}_{50}$ and $\mathrm{E}_{\max }$ values are expected to be pharmacodynamics end points associated with the properties of the pharmacologic system and the investigation of underlying mechanisms, like receptor expression levels.

UTC is the perception to irritations that precedes a motor event of coughing. The UTC threshold is termed as the initial concentration of capsaicin inducing the UTC sensation without a motor cough event (83). It was proved that UTC can be effectively and reproducibly measured. Dicpinigaitis also reported that gender distribution did not differ in $\mathrm{Cu}$ values, implying that UTC and the motor act of coughing are mediated by different brain regions. However, UTC sensation can be influenced by various factors, such as aging, sex, viral upper respiratory tract infection, exercising and voluntary hyperpnea etc. (84-86). As mentioned above, UTC may be a potentially validated indicator of cough challenge test in the future.

\section{Mechanical cough challenges}

Besides cough inhalation challenges, mechanical cough challenges have also been developed to measure cough sensitivity to mechanical stimulation in recent years. Mechanical activation of A $\delta$-fibers and RARs can also elicit cough. Thus, it is not comprehensive to assess cough sensitivity partly by traditional cough challenge tests. Detecting cough sensitivity to mechanical stimulation is also essential in the assessment of cough sensitivity.

\section{Airway vibration stimulation}

The airway vibration induces cough by stimulating airways and RARs directly. In anaesthetised animals, cough has been induced with an invasive intra-tracheal stimulation by bristles or iron slugs $(14,87)$. Dr. Kamimura investigated the clinical usefulness of three cough challenge tests in patients with cough, including (I) tracheal compression test (TCT): the cervical trachea was compressed softly with the fingers several times; (II) tracheal stretch test (TST): the trachea was stretched by retroflexion of the neck; (III) tuning fork test (TFT): vibratory stimulation was provided by placing a tuning fork on the cervical trachea for 20s. The TCT elicited cough in $27.7 \%$ of subjects with cough, the TST in $39.8 \%$ and the TFT in $36.9 \%$. The provocation of cough and an itchy sensation was more frequent in phonationinduced cough and then reversed after improvement of the cough (88). There are some limitations in vibration strength and short duration causing low reproducibility and sensitivity.

Besides, Eccles and Lee applied a modified men's shaver directly to the trachea in patients with URTI to induce cough (89), and showed that the cough was much more apparent in the URTI group. Recently, our team established an airway vibration test with a vibratory device. In our study, we find patients with chronic cough, especially with CVA and GERC, significantly showed a positive response (cough or urge to cough) to airway vibration (unpublished data).

\section{Chest percussion stimulation}

Chest percussion can induce cough by stimulating of RARs which are particularly sensitive to mechanical stimuli. It is applied to facilitate clearance of airway secretions in patients with chronic obstructive pulmonary disease (COPD) or idiopathic pulmonary fibrosis (IPF) by producing chest wall vibration. Lee and Eccles reported that cough could be induced in patients with acute upper 
Table 1 Issues relevant to the utility of the methods in measuring cough sensitivity

\begin{tabular}{|c|c|}
\hline Current challenges & Disadvantages and influential factors \\
\hline Others & Age, gender, smoking, sweeteners, cough suppressants (i.e., menthol) etc. \\
\hline
\end{tabular}

respiratory tract infection by chest percussion compared with healthy controls (90). About $85 \%$ of the URTI subjects coughed while applying the chest percussion. In the subjective questionnaires, more subjects with URTI felt an urge to cough compared to healthy subjects. Another study on the mechanical induction of cough in IPF have also demonstrated that patients with IPF had an enhanced cough sensitivity while healthy controls showed little or even no cough (91). This study on IPF indicated that the lung distortion contributes to refractory cough in IPF. These results were consistent with previous studies in URTI, showing that patients with IPF also presented a heightened cough reflex and related respiratory sensation in the percussion stimulation.

\section{Arnold nerve reflex (ANR)}

The ANR describes the cough arising from mechanical stimulation of the external auditory canal, which is innervated by the auditory branch of the vagus nerves (ABVN) (Arnold nerve) $(92,93)$. Previous studies found that the elicitation rate of ANR ranged from 2\% to $4 \%$ $(93,94)$. In Dicpinigaitis's study, the incidence of ANR presented in about $25 \%(95,96)$, while our study presented the incidence in $8.7 \%$ (97). This difference might be associated with ethnicity. Even though ANR was more common in patients with chronic cough, no disparities were found among different causes of chronic cough (97). Ryan presented two chronic cough cases where positive ANR and successful treatment with gabapentin suggested a vagal neuropathic origin to chronic cough (98). These phenomena support the concept of CHS associated with vagal neuropathy. Moreover, we demonstrated that the therapeutic intervention alleviated positive ANR response with the improvement of cough symptoms. Considering of the low prevalence of ANR in chronic cough patients, ANR appears to suggest the mechanism of the vagus nerve, rather than to act as a method to assess sensitivity.

\section{Current challenges}

There are some factors affecting the accuracy of outcomes in the experimentally induced cough, which should be considered in the cough inhalation challenges. Issues relevant to the use of cough challenge tests are discussed as below (Table 1).

\section{Inconsistency with objective measurements}

Cough threshold may not always seem consistent with cough frequency. In some situations, capsaicin cough sensitivity does not show a good correlation with cough frequency, which might not be an important determinant of cough symptom. For example, in children with recurrent cough, measures of cough sensitivity with capsaicin inhalation weakly relate with cough frequency while subjective cough scores related strongly and consistently with cough frequency (99). The relationship between cough reflex sensitivity (C2 and C5 values) and cough frequency was also demonstrated to be limited in adults with chronic cough by Decalmer (100). Moreover, Khalid proved that cough frequency was not reduced in patients with refractory chronic cough while cough sensitivity to capsaicin was improved by an oral TRPV1 antagonist (33). These phenomena implied a complex relation between cough sensitivity and the symptom due to an existence of the heterogeneity of cough. Recently, Morice reported that cough severity and frequency were decreased among chronic cough subjects after using gefapixant, a P2X3 antagonist. However, with the improvement of the symptom, no ameliorations of cough sensitivity (both C2 
and C5 values) were reported in capsaicin or citric acid challenge but significant decreases of cough sensitivity were seen in ATP and distilled water. This trial revealed multiple pathways in modulating cough (43).

\section{More sensitive end points}

While measuring cough threshold, there exists a potential overlap between health and respiratory diseases. The traditional end points $\mathrm{C} 2$ and $\mathrm{C} 5$ display extensive overlaps between healthy people and patients with chronic cough, which is difficult to discriminate patients with cough from healthy subjects. For example, Decalmer pointed out that normal volunteers had a heightened capsaicin cough sensitivity in the absence of symptoms (100). A significant overlap of values was reported to be obtained between health and disease by Prudon (101). Regarding this issue, Hilton put forward dose-response parameters, $\mathrm{ED}_{50}$ and $\mathrm{E}_{\max }$ values as new endpoints to better discriminate health from disease. Meanwhile, $\mathrm{E}_{\max }$ values were reported to have stronger relations with the prediction of spontaneous 24-hour cough frequency and therefore, might provide a clue to cough mechanisms (81). In patients with mildto-moderate asthma, $\mathrm{ED}_{50}$ and $\mathrm{E}_{\max }$ values were examined to be indications of increased excitability of the neural pathways mediating cough (82). Hence, the utilities of $\mathrm{ED}_{50}$ and $\mathrm{E}_{\max }$ values should be fully elucidated in future studies related to the properties of the pharmacologic system. Furthermore, as reported by Dicpinigaitis (85), the urge to cough threshold might present a relevant end point to measure cough reflex sensitivity, which firstly occurs without an associated motor cough in capsaicin inhalation challenge. Thus, a more sensitive end point requires to be established in the evaluation of potential antitussive agents.

\section{Pharmacological effects of tussive agents}

The placebo effect is a belief in the treatment triggering an improvement of cough, which may influence brain cough suppression. A placebo effect was described in assessing the antitussive effect of dextromethorphan by using citric acid challenge (102). The magnitude of the placebo response was also discussed in the treatment of cough due to acute upper respiratory tract infection. A placebo effect was reported to be responsible for a majority of the reduction in both frequency and sensitivity of cough associated with URTI while only a minority of the improvement was attribute to the active agent. Endogenous opioid neurotransmitters might modulate the placebo effect in some studies on the analgesics $(103,104)$. Besides, a demulcent effect of a syrup and spontaneous recovery of the patient might exert the antitussive placebo response (105). Narcotic opioids such as codeine, morphine and dihydrocodeine are good antitussive agents via their activations on central mu opioid receptors (106). A better understanding of the placebo effect will improve the design of methodologies of cough sensitivity assessment.

Different levels of tachyphylaxis appears in repeated cough challenges with capsaicin, citric acid and distilled water. Marked tachyphylaxis occurs on repeated cough challenges in a short term, presenting a rapid development of tolerance to latter incremental applications of tussive agents. Fujimura has demonstrated that previous administration of capsaicin reduced the subsequent cough response to capsaicin inhalation (tachyphylaxis) in patients with sinobronchial syndrome, which indicates that chronic airway inflammation and its inflammatory products may be the influential factors (107). Morice examined the acute and long-term tachyphylaxis of different repeated challenges. In this study, capsaicin was suggested to be a relatively optimal tussive agent in cough inhalation test because the response to capsaicin adapts more slowly than citric acid and distilled water. As previous report of Morice, tachyphylaxis might be associated with the effects on the interaction between capsaicin and citric acid challenges, which would induce decreased cough responses to one another. These effects might last for at least 6 hours (108). Thus, investigators should be aware of the potential effects of tachyphylaxis on the cough inhalation tests.

\section{Other influential factors}

Responses to cough challenges might be influenced by a variety of factors like gender, age, smoking etc. Underlying mechanisms of gender remains unclear. Possible explanations include sex hormones, gene polymorphism and gender-related difference in anatomic structure. A study showed that capsaicin cough sensitivity was influenced by level of female sex hormones in women normal menstrual cycle. Subjective perception-urge to cough elicited by capsaicin was increased prior to menstruation (109). The reason may be related to the expression of TRPV1 under the influence of sex hormones (110). Furthermore, inflammatory cells like mast cells, eosinophils and neutrophils, are known to express receptors for female 
sexual hormones and commonly seen in the bronchoalveolar lavage in patients with chronic cough (111). As to gene polymorphism, Mukae found that the frequencies of the TT genotype and T allele in bradykinin B (2) receptor gene were significantly increased in the subjects with angiotensin-converting enzyme (ACE) inhibitor-related cough, especially in women. This phenomenon may be associated with the increased transcriptional activity of the promoter, leading to increased bradykinin production and increased cough sensitivity (112). The gender-related difference may also involve in an enhanced sensitivity of airway sensory afferents and central processing of cough sensation $(111,113)$. Additionally, age might be a potential influential factor of cough sensitivity. For instance, both Lai (114) and Song (115) described elderly females with an enhanced cough sensitivity to capsaicin. Moreover, cough response to inhaled distilled water in the elderly was also significantly lower than that in the young healthy subjects (116). Furthermore, other factors might also be involved in the development of cough sensitivity, including smoking, sweeteners, cough suppressants such as menthol and PM2.5 (117-119). Therefore, multiple factors should be considered into the experimental design and data analysis of cough sensitivity.

\section{Conclusions}

The measurement of cough sensitivity is beneficial for a better understanding of the causes and pathogenesis of cough hypersensitivity. There are a range of tools to assess cough reflex sensitivity, including subjective and objective methods. However, there exists some limitations in the developed measurement methods. Thus, further researches should focus on establishing a standardized methods of cough sensitivity measurement. An endpoint with higher sensitivity to indicate cough sensitivity still requires to be investigated to move forward. Furthermore, Cough sensitivity needs to be comprehensively assessed by a combination of cough challenge tests and the symptom of cough, which will potentially shed light on identification of novel therapies. Regarding the cough sensitivity evaluation, different expert committees (e.g., European Respiratory Society, American College of Chest Physician, Chinese Thoracic Society, Japanese Respiratory Society) published a series of consensus statements and guidelines. In the future, with a greater improvement and uniformity of cough inhalation test, more optimal tools will be recommended to reflect the sensitivity of cough reflex.

\section{Acknowledgments}

Funding: This study was supported by grants from the National Natural Science Foundation of China (81870079), State Key Laboratory of Respiratory Disease (SKLRDQN-201702), and the Undergraduate Innovation and Entrepreneurship Training Program of Guangdong Province (201810570041).

\section{Footnote}

Provenance and Peer Review: This article was commissioned by the Guest Editor (Kefang Lai) for the series "3rd International Cough Conference" published in fournal of Thoracic Disease. The article was sent for external peer review.

Conflicts of Interest: All authors have completed the ICMJE uniform disclosure form (available at http:// dx.doi.org/10.21037/jtd-2020-icc-005). The series "3rd International Cough Conference" was commissioned by the editorial office without any funding or sponsorship. KL serves as the unpaid Guest Editor of the series and serves as an unpaid editorial board member of Fournal of Thoracic Disease. The authors have no other conflicts of interest to declare.

Ethical Statement: The authors are accountable for all aspects of the work in ensuring that questions related to the accuracy or integrity of any part of the work are appropriately investigated and resolved.

Open Access Statement: This is an Open Access article distributed in accordance with the Creative Commons Attribution-NonCommercial-NoDerivs 4.0 International License (CC BY-NC-ND 4.0), which permits the noncommercial replication and distribution of the article with the strict proviso that no changes or edits are made and the original work is properly cited (including links to both the formal publication through the relevant DOI and the license). See: https://creativecommons.org/licenses/by-nc-nd/4.0/.

\section{References}

1. Song WJ, Chang YS, Faruqi S, et al. The global epidemiology of chronic cough in adults: a systematic review and meta-analysis. Eur Respir J 2015;45:1479-81.

2. Lai K. Chinese National Guidelines on Diagnosis and 
Management of Cough: consensus and controversy. J Thorac Dis 2014;6:S683-8.

3. Lee KK, Matos S, Evans DH, et al. A longitudinal assessment of acute cough. Am J Respir Crit Care Med 2013;187:991-7.

4. Birring SS, Prudon B, Carr AJ, et al. Development of a symptom specific health status measure for patients with chronic cough: Leicester Cough Questionnaire (LCQ). Thorax 2003;58:339-43.

5. French CT, Irwin RS, Fletcher KE, et al. Evaluation of a cough-specific quality-of-life questionnaire. Chest 2002;121:1123-31.

6. Coyle MA, Keenan DB, Henderson LS, et al. Evaluation of an ambulatory system for the quantification of cough frequency in patients with chronic obstructive pulmonary disease. Cough 2005;1:3-7.

7. Vizel E, Yigla M, Goryachev Y, et al. Validation of an ambulatory cough detection and counting application using voluntary cough under different conditions. Cough 2010;6:3-8.

8. Barton A, Gaydecki P, Holt K, et al. Data reduction for cough studies using distribution of audio frequency content. Cough 2012;8:12-7.

9. Birring SS, Fleming T, Matos S, et al. The Leicester Cough Monitor: preliminary validation of an automated cough detection system in chronic cough. Eur Respir J 2008;31:1013-8.

10. Canning BJ. Afferent nerves regulating the cough reflex: mechanisms and mediators of cough in disease. Otolaryngol Clin North Am 2010;43:15-25-vii.

11. Canning BJ, Chang AB, Bolser DC, et al. Anatomy and neurophysiology of cough: CHEST Guideline and Expert Panel report. Chest 2014;146:1633-48.

12. Morice AH, Kastelik JA, Thompson R. Cough challenge in the assessment of cough reflex. Br J Clin Pharmacol 2001;52:365-75.

13. Mazzone SB, Farrell MJ. Heterogeneity of cough neurobiology: Clinical implications. Pulm Pharmacol Ther 2019;55:62-6.

14. Widdicombe JG. Receptors in the trachea and bronchi of the cat. J Physiol 1954;123:71-104.

15. Canning BJ, Chou YL. Cough sensors. I. Physiological and pharmacological properties of the afferent nerves regulating cough. Handb Exp Pharmacol 2009;187:23-47.

16. Morice AH, Millqvist E, Belvisi MG, et al. Expert opinion on the cough hypersensitivity syndrome in respiratory medicine. Eur Respir J 2014;44:1132-48.

17. Javorkova N, Hajtmanova E, Kostkova L, et al. Changes of cough reflex sensitivity induced by cancer radiotherapy of chest and neck regions. J Physiol Pharmacol 2006;57:157-63.

18. Ebihara S, Saito H, Kanda A, et al. Impaired efficacy of cough in patients with Parkinson disease. Chest 2003;124:1009-15.

19. Troche MS, Brandimore AE, Okun MS, et al. Decreased cough sensitivity and aspiration in Parkinson disease. Chest 2014;146:1294-9.

20. Parkerson J, Ledford D. Mannitol as an indirect bronchoprovocation test for the 21st century. Ann Allergy Asthma Immunol 2011;106:91-6.

21. Dicpinigaitis PV. Short- and long-term reproducibility of capsaicin cough challenge testing. Pulm Pharmacol Ther 2003;16:61-5.

22. Curtis JA, Troche MS. Handheld Cough Testing: A Novel Tool for Cough Assessment and Dysphagia Screening. Dysphagia 2020;18:1312-8.

23. Fujiwara K, Kawamoto K, Shimizu Y, et al. A novel reflex cough testing device. BMC Pulm Med 2017;17:19-7.

24. Groneberg DA, Niimi A, Dinh QT, et al. Increased expression of transient receptor potential vanilloid-1 in airway nerves of chronic cough. Am J Respir Crit Care Med 2004;170:1276-80.

25. Nieto L, de Diego A, Perpiñá M, et al. Cough reflex testing with inhaled capsaicin in the study of chronic cough. Respir Med 2003;97:393-400.

26. Dicpinigaitis PV, Alva RV. Safety of capsaicin cough challenge testing. Chest 2005;128:196-202.

27. Wang R, Fowler SJ, Niven R, et al. Investigating the safety of capsaicin cough challenge in severe asthma. Clin Exp Allergy 2019;49:932-4.

28. Morice AH, Fontana GA, Belvisi MG, et al. ERS guidelines on the assessment of cough. Eur Respir J 2007;29:1256-76.

29. Boulet LP, Coeytaux RR, McCrory DC, et al. Tools for assessing outcomes in studies of chronic cough: CHEST guideline and expert panel report. Chest 2015;147:804-14.

30. Lai K, Shen H, Zhou X, et al. Clinical Practice Guidelines for Diagnosis and Management of Cough-Chinese Thoracic Society (CTS) Asthma Consortium. J Thorac Dis 2018;10:6314-51.

31. Dicpinigaitis PV, Tibb AS, Ramsey DL, et al. Stability of cough reflex sensitivity during viral upper respiratory tract infection (common cold). Pulm Pharmacol Ther 2014;28:154-7.

32. Long L, Yao H, Tian J, et al. Heterogeneity of cough hypersensitivity mediated by TRPV1 and TRPA1 in 
patients with chronic refractory cough. Respir Res 2019;20:112-9.

33. Khalid S, Murdoch R, Newlands A, et al. Transient receptor potential vanilloid 1 (TRPV1) antagonism in patients with refractory chronic cough: a double-blind randomized controlled trial. J Allergy Clin Immunol 2014;134:56-62.

34. Belvisi MG, Birrell MA, Wortley MA, et al. XEN-D0501, a Novel Transient Receptor Potential Vanilloid 1 Antagonist, Does Not Reduce Cough in Patients with Refractory Cough. Am J Respir Crit Care Med 2017;196:1255-63.

35. Foster G, Yeo WW, Ramsay LE. Effect of sulindac on the cough reflex of healthy subjects. Br J Clin Pharmacol 1991;31:207-8.

36. Dicpinigaitis PV, Dobkin JB. Effect of zafirlukast on cough reflex sensitivity in asthmatics. J Asthma 1999;36:265-70.

37. Dicpinigaitis PV, Dobkin JB, Rauf K, et al. Inhibition of capsaicin-induced cough by the gamma-aminobutyric acid agonist baclofen. J Clin Pharmacol 1998;38:364-7.

38. Millqvist E, Ternesten-Hasséus E, Bende M. Inhalation of menthol reduces capsaicin cough sensitivity and influences inspiratory flows in chronic cough. Respir Med 2013;107:433-8.

39. Fukumitsu K, Kanemitsu Y, Asano T, et al. Tiotropium Attenuates Refractory Cough and Capsaicin Cough Reflex Sensitivity in Patients with Asthma. J Allergy Clin Immunol Pract 2018;6:1613-1620.e2.

40. Ford AP, Undem BJ. The therapeutic promise of ATP antagonism at $\mathrm{P} 2 \mathrm{X} 3$ receptors in respiratory and urological disorders. Front Cell Neurosci 2013;7:267.

41. Fowles HE, Rowland T, Wright C, et al. Tussive challenge with ATP and AMP: does it reveal cough hypersensitivity? Eur Respir J 2017;49:1601452.

42. Basoglu OK, Pelleg A, Essilfie-Quaye S, et al. Effects of aerosolized adenosine 5 '-triphosphate vs adenosine 5-'monophosphate on dyspnea and airway caliber in healthy nonsmokers and patients with asthma. Chest 2005;128:1905-9.

43. Morice AH, Kitt MM, Ford AP, et al. The effect of gefapixant, a P2X3 antagonist, on cough reflex sensitivity: a randomised placebo-controlled study. Eur Respir J 2019;54:1900439.

44. Bonvini SJ, Birrell MA, Grace MS, et al. Transient receptor potential cation channel, subfamily $\mathrm{V}$, member 4 and airway sensory afferent activation: Role of adenosine triphosphate. J Allergy Clin Immunol 2016;138:249-261.e12.
45. Abdulqawi R, Dockry R, Holt K, et al. P2X3 receptor antagonist (AF-219) in refractory chronic cough: a randomised, double-blind, placebo-controlled phase 2 study. Lancet 2015;385:1198-205.

46. Pelleg A, Xu F, Zhuang J, et al. DT-0111: a novel drugcandidate for the treatment of COPD and chronic cough. Ther Adv Respir Dis 2019;13:1753466619877960.

47. Knag Pedersen S, Ustrup AS, Baarnes CB, et al. Usefulness of mannitol challenge testing for diagnosing asthma in everyday clinical practice. J Asthma 2020;57:663-9.

48. Brannan JD, Anderson SD, Perry CP, et al. The safety and efficacy of inhaled dry powder mannitol as a bronchial provocation test for airway hyperresponsiveness: a phase 3 comparison study with hypertonic (4.5\%) saline. Respir Res 2005;6:144-12.

49. Koskela HO, Hyvärinen L, Brannan JD, et al. Coughing during mannitol challenge is associated with asthma. Chest 2004;125:1985-92.

50. Belvisi MG, Birrell MA. The emerging role of transient receptor potential channels in chronic lung disease. Eur Respir J 2017;50:1601357.

51. Koskela HO, Lake C, Wong K, et al. Cough sensitivity to mannitol inhalation challenge identifies subjects with chronic cough. Eur Respir J 2018;51:1800294.

52. Fox AJ, Barnes PJ, Dray A. Stimulation of guineapig tracheal afferent fibres by non-isosmotic and lowchloride stimuli and the effect of frusemide. J Physiol 1995;482:179-87.

53. Koskela HO, Kontra KM, Purokivi MK, et al. Interpretation of cough provoked by airway challenges. Chest 2005;128:3329-35.

54. Koskela HO, Purokivi MK, Kontra KM, et al. Hypertonic saline cough provocation test with salbutamol pretreatment: evidence for sensorineural dysfunction in asthma. Clin Exp Allergy 2008;38:1100-7.

55. Cheney FW, Butler J. The effects of ultrasonicallyproduced aerosols on airway resistance in man. Anesthesiology 1968;29:1099-106.

56. Sheppard D, Rizk NW, Boushey HA, et al. Mechanism of cough and bronchoconstriction induced by distilled water aerosol. Am Rev Respir Dis 1983;127:691-4.

57. Fontana GA, Pantaleo T, Lavorini F, et al. Repeatability of cough-related variables during fog challenges at threshold and suprathreshold stimulus intensity in humans. Eur Respir J 1999;13:1447-50.

58. Eschenbacher WL, Boushey HA, Sheppard D. Alteration in osmolarity of inhaled aerosols cause bronchoconstriction and cough, but absence of a permeant anion causes cough 
alone. Am Rev Respir Dis 1984;129:211-5.

59. Fahey JW, Zalcmann AT, Talalay P. The chemical diversity and distribution of glucosinolates and isothiocyanates among plants. Phytochemistry 2001;56:5-51.

60. Brozmanova M, Mazurova L, Ru F, et al. Comparison of TRPA1-versus TRPV1-mediated cough in guinea pigs. Eur J Pharmacol 2012;689:211-8.

61. Andrè E, Gatti R, Trevisani M, et al. Transient receptor potential ankyrin receptor 1 is a novel target for protussive agents. Br J Pharmacol 2009;158:1621-8.

62. Lehto SG, Weyer AD, Youngblood BD, et al. Selective antagonism of TRPA1 produces limited efficacy in models of inflammatory- and neuropathicinduced mechanical hypersensitivity in rats. Mol Pain 2016;12:174480691667776.

63. Birrell MA, Belvisi MG, Grace M, et al. TRPA1 agonists evoke coughing in guinea pig and human volunteers. Am J Respir Crit Care Med 2009;180:1042-7.

64. Wallace E, Guiu Hernandez E, Ang A, et al. A systematic review of methods of citric acid cough reflex testing. Pulm Pharmacol Ther 2019;58:101827.

65. Lalloo UG, Fox AJ, Belvisi MG, et al. Capsazepine inhibits cough induced by capsaicin and citric acid but not by hypertonic saline in guinea pigs. J Appl Physiol 1995;79:1082-7.

66. Grace MS, Dubuis E, Birrell MA, et al. Pre-clinical studies in cough research: role of Transient Receptor Potential (TRP) channels. Pulm Pharmacol Ther 2013;26:498-507.

67. Buday T, Kovacikova L, Ruzinak R, et al. TRPV4 antagonist GSK2193874 does not modulate cough response to osmotic stimuli. Respir Physiol Neurobiol 2017;236:1-4.

68. Bickerman HA, Barach AL. The experimental production of cough in human subjects induced by citric acid aerosols; preliminary studies on the evaluation of antitussive agents. Am J Med Sci 1954;228:156-63.

69. Nurmi HM, Lätti AM, Brannan JD, et al. Comparison of mannitol and citric acid cough provocation tests. Respir Med 2019;158:14-20.

70. Morice AH, Marshall AE, Higgins KS, et al. Effect of inhaled menthol on citric acid induced cough in normal subjects. Thorax 1994;49:1024-6.

71. Packman EW, Ciccone PE, Wilson J, et al. Antitussive effects of diphenhydramine on the citric acid aerosolinduced cough response in humans. Int J Clin Pharmacol Ther Toxicol 1991;29:218-22.

72. Dicpinigaitis PV, Canning BJ, Garner R, et al. Effect of memantine on cough reflex sensitivity: translational studies in guinea pigs and humans. J Pharmacol Exp Ther 2015;352:448-54.

73. Svajdova S, Buday T, Brozmanova M. Lidocaine, a Nonselective Inhibitor of Voltage-Gated Sodium Channels, Blocks Chemically-Induced Cough in Awake Naïve Guinea Pigs. Adv Exp Med Biol 2019;1160:1-9.

74. Grattan TJ, Marshall AE, Higgins KS, et al. The effect of inhaled and oral dextromethorphan on citric acid induced cough in man. Br J Clin Pharmacol 1995;39:261-3.

75. Wong CH, Matai R, Morice AH. Cough induced by low pH. Respir Med 1999;93:58-61.

76. Kollarik M, Ru F, Undem BJ. Acid-sensitive vagal sensory pathways and cough. Pulm Pharmacol Ther 2007;20:402-11.

77. Fujimura M, Sakamoto S, Kamio Y, et al. Sex difference in the inhaled tartaric acid cough threshold in non-atopic healthy subjects. Thorax 1990;45:633-4.

78. Mochizuki H, Shimizu T, Morikawa A, et al. Inhaled diuretics attenuate acid-induced cough in children with asthma. Chest 1995;107:413-7.

79. Fujimura M, Kamio Y, Myou S, et al. Effect of oral mexiletine on the cough response to capsaicin and tartaric acid. Thorax 2000;55:126-8.

80. Fontana GA, Pantaleo T, Lavorini F, et al. A noninvasive electromyographic study on threshold and intensity of cough in humans. Eur Respir J 1997;10:983-9.

81. Hilton ECY, Baverel PG, Woodcock A, et al. Pharmacodynamic modeling of cough responses to capsaicin inhalation calls into question the utility of the C5 end point. J Allergy Clin Immunol 2013;132:847-55.e1-5.

82. Satia I, Tsamandouras N, Holt K, et al. Capsaicinevoked cough responses in asthmatic patients: Evidence for airway neuronal dysfunction. J Allergy Clin Immunol 2017;139:771-779.e10.

83. Dicpinigaitis $\mathrm{PV}$, Rhoton WA, Bhat $\mathrm{R}$, et al. Investigation of the urge-to-cough sensation in healthy volunteers. Respirology 2012;17:337-41.

84. Ebihara S, Ebihara T, Kanezaki M, et al. Aging deteriorated perception of urge-to-cough without changing cough reflex threshold to citric acid in female never-smokers. Cough 2011;7:3-6.

85. Dicpinigaitis PV, Bhat $\mathrm{R}$, Rhoton WA, et al. Effect of viral upper respiratory tract infection on the urge-to-cough sensation. Respir Med 2011;105:615-8.

86. Fontana GA. Downregulation of cough by exercise and voluntary hyperpnea. Lung 2010;188:S95-8.

87. Tedeschi RE, Tedeschi DH, Hitchens JT, et al. A new antitussive method involving mechanical stimulation 
in unanesthetized dogs. J Pharmacol Exp Ther 1959;126:338-44.

88. Kamimura M, Mouri A, Takayama K, et al. Cough challenge tests involving mechanical stimulation of the cervical trachea in patients with cough as a leading symptom. Respirology 2010;15:1244-51.

89. Lee P, Eccles R. Cough induced by mechanical stimulation of the upper airway in humans. Acta Otolaryngol 2004;124:720-5.

90. Lee PCL, Eccles R. Cough induction by high-frequency chest percussion in healthy volunteers and patients with common cold. Respir Med 2004;98:771-6.

91. Jones RM, Hilldrup S, Hope-Gill BD, et al. Mechanical induction of cough in Idiopathic Pulmonary Fibrosis. Cough 2011;7:2-10.

92. Bloustine S, Langston L, Miller T. Ear-cough (Arnold's) reflex. Ann Otol Rhinol Laryngol 1976;85:406-7.

93. Tekdemir I, Aslan A, Elhan A. A clinico-anatomic study of the auricular branch of the vagus nerve and Arnold's earcough reflex. Surg Radiol Anat 1998;20:253-7.

94. Gupta D, Verma S, Vishwakarma SK. Anatomic basis of Arnold's ear-cough reflex. Surg Radiol Anat 1986;8:217-20.

95. Dicpinigaitis PV, Kantar A, Enilari O, et al. Prevalence of Arnold Nerve Reflex in Adults and Children With Chronic Cough. Chest 2018;153:675-9.

96. Dicpinigaitis PV, Enilari O, Cleven KL. Prevalence of Arnold nerve reflex in subjects with and without chronic cough: Relevance to Cough Hypersensitivity Syndrome. Pulm Pharmacol Ther 2019;54:22-4.

97. Mai Y, Zhan C, Zhang S, et al. Arnold Nerve Reflex: Vagal Hypersensitivity in Chronic Cough With Various Causes. Chest 2020;158:264-71.

98. Ryan NM, Gibson PG, Birring SS. Arnold's nerve cough reflex: evidence for chronic cough as a sensory vagal neuropathy. J Thorac Dis 2014;6:S748-52.

99. Chang AB, Phelan PD, Robertson CF, et al. Relation between measurements of cough severity. Arch Dis Child 2003;88:57-60.

100. Decalmer SC, Webster D, Kelsall AA, et al. Chronic cough: how do cough reflex sensitivity and subjective assessments correlate with objective cough counts during ambulatory monitoring? Thorax 2007;62:329-34.

101. Prudon B, Birring SS, Vara DD, et al. Cough and glottic-stop reflex sensitivity in health and disease. Chest 2005;127:550-7.

102. Rostami-Hodjegan A, Abdul-Manap R, Wright CE, et al. The placebo response to citric acid-induced cough: pharmacodynamics and gender differences. Pulm
Pharmacol Ther 2001;14:315-9.

103. Benedetti F, Amanzio M. The neurobiology of placebo analgesia: from endogenous opioids to cholecystokinin. Prog Neurobiol 1997;52:109-25.

104. Riet ter G, de Craen AJ, de Boer A, et al. Is placebo analgesia mediated by endogenous opioids? A systematic review. Pain 1998;76:273-5.

105.Fuller RW, Jackson DM. Physiology and treatment of cough. Thorax 1990;45:425-30.

106. Kamei J. Role of opioidergic and serotonergic mechanisms in cough and antitussives. Pulm Pharmacol 1996;9:349-56.

107. Fujimura M, Kamio Y, Sakamoto S, et al. Tachyphylaxis to capsaicin-induced cough and its reversal by indomethacin, in patients with the sinobronchial syndrome. Clin Auton Res 1992;2:397-401.

108. Morice AH, Higgins KS, Yeo WW. Adaptation of cough reflex with different types of stimulation. Eur Respir J 1992;5:841-7.

109. Kavalcikova-Bogdanova N, Kovacikova L, Buday T, et al. Sensitivity of airway cough-related afferents is influenced by female sex hormones. Respir Physiol Neurobiol 2018;257:12-7.

110. Kvachadze I, Tsagareli MG, Dumbadze Z. An overview of ethnic and gender differences in pain sensation. Georgian Med News 2015;(238):102-8.

111. Kavalcikova-Bogdanova N, Buday T, Plevkova J, et al. Chronic Cough as a Female Gender Issue. Adv Exp Med Biol 2016;905:69-78.

112. Mukae S, Aoki S, Itoh S, et al. Bradykinin B(2) receptor gene polymorphism is associated with angiotensinconverting enzyme inhibitor-related cough. Hypertension 2000;36:127-31.

113. Morice AH, Jakes AD, Faruqi S, et al. A worldwide survey of chronic cough: a manifestation of enhanced somatosensory response. Eur Respir J 2014;44:1149-55.

114.Lai K, Long L, Yi F, et al. Age and Sex Distribution of Chinese Chronic Cough Patients and Their Relationship with Capsaicin Cough Sensitivity. Allergy Asthma Immunol Res 2019;11:871-84.

115.Song WJ, Kim JY, Jo EJ, et al. Capsaicin cough sensitivity is related to the older female predominant feature in chronic cough patients. Allergy Asthma Immunol Res 2014;6:401-8.

116. Newnham DM, Hamilton SJ. Sensitivity of the cough reflex in young and elderly subjects. Age Ageing 1997;26:185-8.

117.Dicpinigaitis PV, Sitkauskiene B, Stravinskaite K, et al. Effect of smoking cessation on cough reflex sensitivity. Eur 
Respir J 2006;28:786-90.

118. Wise PM, Breslin PAS, Dalton P. Sweet taste and menthol increase cough reflex thresholds. Pulm Pharmacol Ther 2012;25:236-41.

Cite this article as: Mai Y, Fang L, Zhong S, de Silva SD, Chen R, Lai K. Methods for assessing cough sensitivity. J Thorac Dis 2020;12(9):5224-5237. doi: 10.21037/jtd-2020-icc-005
119.Lv H, Yue J, Chen Z, et al. Effect of transient receptor potential vanilloid-1 on cough hypersensitivity induced by particulate matter 2.5. Life Sci 2016;151:157-66. 